\title{
Exergy Analysis of a Combined Power and Cooling Cycle
}

\author{
R. KARAALi* \\ Department of Mechanical Engineering, Bayburt University, 69000 Bayburt
}

\begin{abstract}
Ammonia-water power cycles are important for efficient utilization of low temperature heat sources such as geothermal, solar, waste heat sources, etc. For some special conditions ammonia-water power cycle is an important and economical option. This paper presents an exergetic analysis of a combined power and cooling cycle that uses ammonia-water mixture as working fluid. Such cycles, use solar or geothermal energy or waste heat energy from a conventional power cycle. Ammonia-water power cycle can be used as independent cycles to provide power output and cooling. For a range (25-55 Bar) of boiler pressure the performance of the combined power and cooling cycle is investigated. The exergy of the boiler is very low compared to its energy. There is a boiling process and a heat transfer process at low temperature, both of which destruct the energy given to the boiler, so that the energy efficiency is low; however the exergy efficiency is higher than the energy efficiency. Increasing the turbine inlet pressure decreases the energy and exergy efficiencies.
\end{abstract}

DOI: 10.12693/APhysPolA.130.209

PACS/topics: 88.05.Sv, 88.10.cn, 88.20.tf

\section{Introduction}

In many industrial processes, there is a need for electric power and cooling at low temperatures especially in food, cold storage, and chemical industry. In some conditions ammonia-water power cycle is an economical option. In order to prevent the destruction of environment and global warming, natural working fluids such as ammonia, water and other organic refrigerants have been getting increased attention. Thermal power cycles have been improving over the past hundred years. To increase their thermal efficiency many efficient methods have been found and experimented. For some working conditions, the ammonia-water cycle produces more power than the Rankine cycle and this cycle can be used as a bottoming cycle for gas turbines, gas engines, diesel engines, geothermal power cycles, and other industrial power cycles. The maximum power can be produced by the Lorentz cycle, for finite heat source and sink reservoirs. For the most of applications in industry, Kalina cycle that uses ammonia-water mixture as the working fluid, have higher efficiency than Rankine cycle [1]. Cho et al. in their review on combined cooling, heating and power performance improvement summarize the methods used to perform energetic-exergetic analyses, system optimization and performance improvement studies [2].

Kalina cycle, Goswami cycle and other different kinds of cycles can be obtained by adding new components into the ammonia-water cycle. Ammonia and water make a non-azeotropic mixture which boils with an increasing temperature. The ammonia-water mixture properties are well studied in the literature. However, to use the low temperature waste heat sources effectively, there is a need in industry to improve the efficiency of the ammoniawater cycle. Kalina has proposed a cycle in 1980s that

\footnotetext{
*e-mail: rabikar@gmail.com
}

uses ammonia-water mixture and has shown that this cycle has better efficiency than the combined cycle using the Rankine bottoming cycle [3]. Zare et al. have obtained the exergetic efficiency of this cycle for high temperatures, with a value of about $50 \%$, in their articles on ammonia-water power/cooling cycle. They have found that increasing inlet temperature of the gas turbine decreases the cooling output and the power and decreases the exergetic efficiency of the cycle $[4,5]$. Dejfors et al. have found in their study [6] that in the ammoniawater power cycles for direct-fired cogeneration applications the net power of the cycle is $4-11 \%$, which is less than that of the Rankine steam cycle. Wang et al. have done the thermodynamic analysis and optimization of an ammonia-water power system with LNG as its heat sink. They also found the optimum turbine inlet pressure needed to reach the maximum net power output [7]. Wang et al., in their latest study, have shown the thermodynamic analysis of a new combined cooling and power system using ammonia-water mixture. A combination of Kalina cycle with ammonia-water refrigeration cycle is introduced to provide power and cooling output more effective than the conventional one. The destructed exergy in the components and in the cycle are calculated and it is found that most of the exergy destruction happens in exhausted heat source and condensers [8].

Jonsson and Yan have found that decreasing the temperature of the waste heat decreases the efficiency of the cycles, in their study about comparing the ammoniawater bottoming cycle for gas and diesel engines, as prime movers [9]. Goswami et al., in their article, have present a novel combined power and cooling cycle. The Goswami cycle has the first and the second law efficiencies of about $23 \%$ and $69 \%$, respectively [10-12].

The goal of this study is to obtain the exergetic analysis of the combined power and cooling systems and the exergetic destruction in the components, which use ammoniawater solutions. 


\section{Description of the cycle}

One of the most effective uses of energy is cogeneration, a simultaneous production of electricity and useful cooling (or heating) from the same fuel or energy source. This cycle consists of two cycles. The first one is the ammonia-water absorption cooling cycle and the second one is the Rankine cycle, producing power. A combined power and cooling cycle includes gas turbine, cooler, absorber, pump, heat exchanger, boiler and pressure reducing valve as can be seen in Fig. 1. Ammonia is not con-

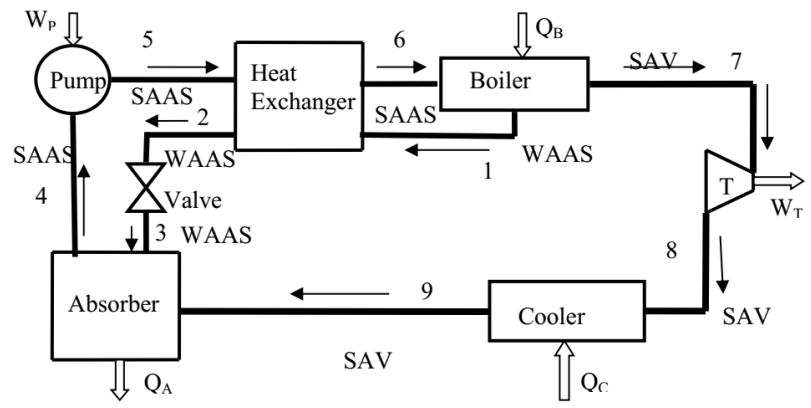

Fig. 1. Ammonia-water combined power and cooling cycle. SAAS - strong aqua-ammonia solution, WAAS — weak aqua-ammonia solution, SAV — superheated ammonia vapor.

densed in the ammonia-water cycle so that the cycle does not have a condenser. The super heated ammonia is expanded in a turbine to obtain power at high temperature and high pressure. After the turbine, the expanded ammonia vapor is used to obtain refrigeration. Three kinds of working fluids are used in the ammonia-water cycle. The first one is the strong ammonia-water solution, the second one is the pure accepted ammonia and the third one is the weak ammonia-water solution. The ammonia vapor evaporates by boiling from the strong ammoniawater solution, and the remaining solution is considered as the weak ammonia-water solution.

In this study, the following assumptions are utilized in the analysis of the cycle: the pump process is adiabatic, the cycle is at steady state and steady flow cycle, pressure drops in the pipeline and in the components are neglected, the turbine expansion is isentropic, the pressure-reducing valve uses an adiabatic process, the concentrations are 0.54 for strong solution and 0.126 for weak solution. The weak and the strong liquids are assumed to be in liquid phase at the states of $1,2,3,4,5$, and 6 . The superheated ammonia vapor is assumed to be in gas phase at the states of 7,8 and 9 .

\section{Analysis of the cycle}

For the cycles using the ammonia-water solution as the working fluid, the thermodynamic properties are very important. For the enthalpy and the entropy values of the ammonia-water solution many equations have been developed in literature. But some of them give error and others are very complicated and are very difficult to use.

To calculate the enthalpy and the entropy values of the ammonia-water mixtures, there are three methods, which can be used. The first one is El-Sayed and Tribus method, the second one is Gibbs free energy method, and the third one is Park and Sonntag method [12].

TABLE I

Mass, energy, and exergy equations for each component and for the overall cycle $[17,18]$.

\begin{tabular}{|c|c|c|c|}
\hline Component & Mass equation & Energy equation & Exergy equation \\
\hline Heat exchanger & $\begin{array}{l}\dot{m}_{1}=\dot{m}_{2} \\
\dot{m}_{5}=\dot{m}_{6}\end{array}$ & $\dot{m}_{1} h_{1}+\dot{m}_{5} h_{5}=\dot{m}_{6} h_{6}+\dot{m}_{2} h_{2}$ & $\begin{array}{l}E_{1}=\dot{m}_{1}\left(h_{1}-h_{0}-T_{0}\left(s_{1}-s_{0}\right)\right) \\
E_{2}=\dot{m}_{2}\left(h_{2}-h_{0}-T_{0}\left(s_{2}-s_{0}\right)\right) \\
E_{5}=\dot{m}_{5}\left(h_{5}-h_{0}-T_{0}\left(s_{5}-s_{0}\right)\right) \\
E_{6}=\dot{m}_{6}\left(h_{6}-h_{0}-T_{0}\left(s_{6}-s_{0}\right)\right)\end{array}$ \\
\hline Absorber & $\dot{m}_{4}=\dot{m}_{9}+\dot{m}_{3}$ & $Q_{\mathrm{A}}=\dot{m}_{9} h_{9}+\dot{m}_{3} h_{3}-\dot{m}_{4} h_{4}$ & $E_{3}=\dot{m}_{3}\left(h_{3}-h_{0}-T_{0}\left(s_{3}-s_{0}\right)\right)$ \\
\hline Pump & $\dot{m}_{4}=\dot{m}_{5}$ & $W_{\mathrm{P}}=\dot{m}_{4}\left(h_{5}-h_{4}\right)$ & $E_{4}=\dot{m}_{4}\left(h_{4}-h_{0}-T_{0}\left(s_{4}-s_{0}\right)\right)$ \\
\hline Boiler & $\dot{m}_{6}=\dot{m}_{7}+\dot{m}_{1}$ & $\dot{m}_{6} h_{6}+Q_{\mathrm{B}}=\dot{m}_{7} h_{7}+\dot{m}_{1} h_{1}$ & $E_{7}=\dot{m}_{7}\left(h_{7}-h_{0}-T_{0}\left(s_{7}-s_{0}\right)\right)$ \\
\hline Turbine & $\dot{m}_{7}=\dot{m}_{8}$ & $W_{\mathrm{T}}=\dot{m}_{7}\left(h_{7}-h_{8}\right)$ & $E_{8}=\dot{m}_{8}\left(h_{8}-h_{0}-T_{0}\left(s_{8}-s_{0}\right)\right)$ \\
\hline Cooler & $\dot{m}_{9}=\dot{m}_{8}$ & $Q_{\mathrm{C}}=\dot{m}_{8}\left(h_{8}-h_{9}\right)$ & $E_{9}=\dot{m}_{9}\left(h_{9}-h_{0}-T_{0}\left(s_{9}-s_{0}\right)\right)$ \\
\hline Overall cycle & $\begin{array}{r}\dot{m}_{\text {sol }} \\
\dot{m}_{\text {solution }} X_{\text {solutior }} \\
\left(Q_{\mathrm{A}}+W_{\mathrm{T}}\right)_{\text {out }}\end{array}$ & $\begin{array}{l}\text { ion }=\dot{m}_{\text {water }}+\dot{m}_{\text {ammonia }} \\
=\dot{m}_{\text {water }} X_{\text {water }}+\dot{m}_{\text {ammonia }} X_{\text {ammonia }} \\
\text { energy } \\
\text { t }_{\mathrm{C}}=\frac{\left(Q_{\mathrm{B}}+W_{\mathrm{P}}+Q_{\mathrm{C}}\right)_{\text {inletenergy }}}{2} \\
W_{\text {Tnet }}=W_{\mathrm{T}}-W_{\mathrm{P}}\end{array}$ & $\begin{array}{c}\eta_{\text {energy }}=\left(Q_{\mathrm{C}}+W_{\text {Tnet }}\right) / Q_{\mathrm{B}} \\
\eta_{\text {exergy }}=\left(E_{\mathrm{QC}}+W_{\text {Tnet }}\right) / E_{\mathrm{QB}} \\
\dot{E}_{\mathrm{C}}=\dot{Q}_{\mathrm{C}}\left(1-\frac{T_{0}}{T_{\mathrm{C}}}\right) \\
\dot{E}_{\mathrm{B}}=\dot{E}_{1}+\dot{E}_{7}-\dot{E}_{6} \\
\dot{E}_{\mathrm{D}, \mathrm{A}}=\dot{E}_{9}+\dot{E}_{3}-\dot{E}_{4} \\
\dot{E}_{\mathrm{D}, \mathrm{HE}}=\dot{E}_{5}+\dot{E}_{1}-\dot{E}_{6}-\dot{E}_{2} \\
\dot{E}_{\mathrm{D}, \mathrm{OC}}=\dot{E}_{\mathrm{Q}, \mathrm{B}}+W_{\mathrm{P}}-W_{\mathrm{T}}-\dot{E}_{\mathrm{Q},} \mathrm{C}\end{array}$ \\
\hline
\end{tabular}


The tables of the enthalpy and the entropy values of the ammonia-water mixtures are used to calculate the values of the streams, in this study [13]. By using Park and Sonntag method the tables are obtained from the Helmholtz free energy equations. For the ammonia-water solution Alamdari has proposed equations, however with the errors reaching above $4 \%$ of the real values [14, 15]. For the absorption cooling cycles, Da-Wen Sun has proposed design data and optimum design maps, which, however, are difficult to use and which are applicable for a limited range [16].

There is no mass inlet or outlet of the cycle so that the chemical exergy of the streams is not taken into calculation. The total exergy is taken as the physical exergy of the streams. In this study the thermodynamic analysis of the cycle, which was introduced in the previous section, is done and the mathematical modeling is explained in the following section. The equations used in the calculation of the cycle are given in Table I for of each component and for overall cycle.

\section{Results and discussion}

The enthalpy and entropy values of the streams are taken from the tables of Ref. [13]. For pure water at 1 atmospheric pressure and at temperature of $273.16 \mathrm{~K}$, the reference state values are $s=0, h=0$ and $u=$ 0 . However, in this study for the sake of simplicity and understandability, for the mixture of water-ammonia, the reference state values are taken at pressure of $100 \mathrm{kPa}$ and temperature of $-50^{\circ} \mathrm{C}$ as $h_{0}=118.47 \mathrm{~kJ} / \mathrm{kg}$ and $s_{0}=0.5659 \mathrm{~kJ} / \mathrm{kg} \mathrm{K}$, which are given in Ref. [13].

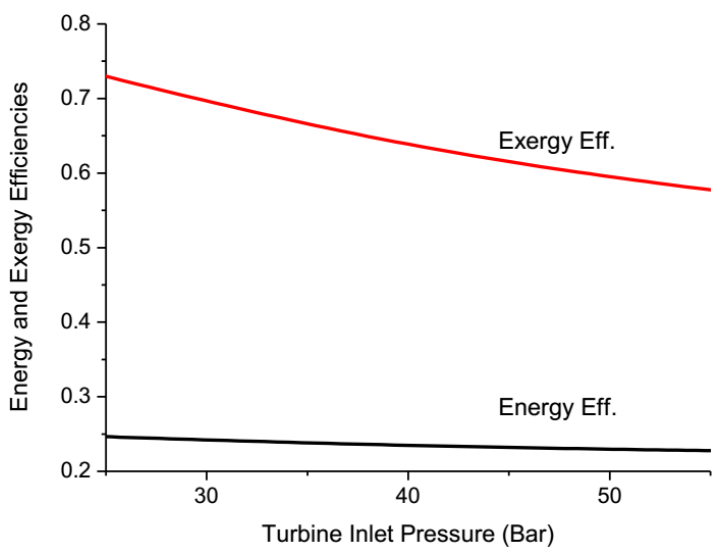

Fig. 2. Variations of exergy and energy efficiencies with the turbine inlet pressure of the ammonia-water cycle.

For each stream of the fluids, the description, the concentration, the phase, the pressure, the temperature, the flow rate value, the enthalpy, the entropy, the exergy and the energy and the heat exergy of each component and the energy balance of the ammonia-water cycle for pump outlet pressure of 40 bar are given in Table II. The reference state values for pure ammonia, which are $u=0$, $h=0$ and $s=0$, are taken at pressure of 1 atmosphere and at temperature of $195.495 \mathrm{~K}$ [13]. However, the reference values in this study are taken for pressure of $100 \mathrm{kPa}$ and temperature of $0^{\circ} \mathrm{C}$, from Ref. [13].

There is heat transfer at low temperature and boiling process in the boiler which both destruct the energy given into it, so that the energy destruction in the boiler is very high as can be seen from Table II. For that reason the exergy efficiency is higher than the energy efficiency.

The variations of exergy and energy efficiencies with the turbine inlet pressure (between 25-55 Bar) of the ammonia-water cycle are given in Fig. 2. Increasing the ammonia-water turbine inlet pressure decreases the exergy and energy efficiencies, which is in good agreement with literature. The optimum turbine inlet pressure can be obtained with an optimization study for each working condition of the ammonia-water cycle.

Variations of the pump and the turbine work with the turbine inlet pressure (between 25-55 Bar) of the ammonia-water cycle are given in Fig. 3. Increasing the turbine inlet pressure increases the pump work but decreases the work obtained from the turbine.

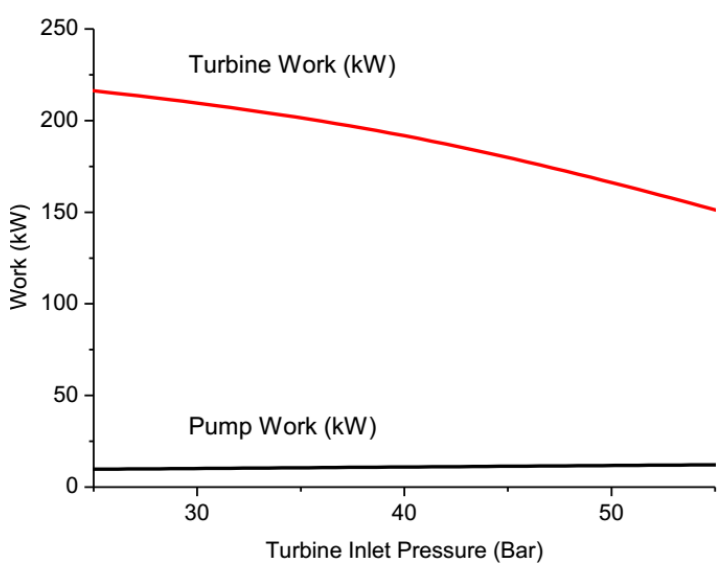

Fig. 3. Variations of the pump and the turbine work with the turbine inlet pressure of the ammonia-water cycle.

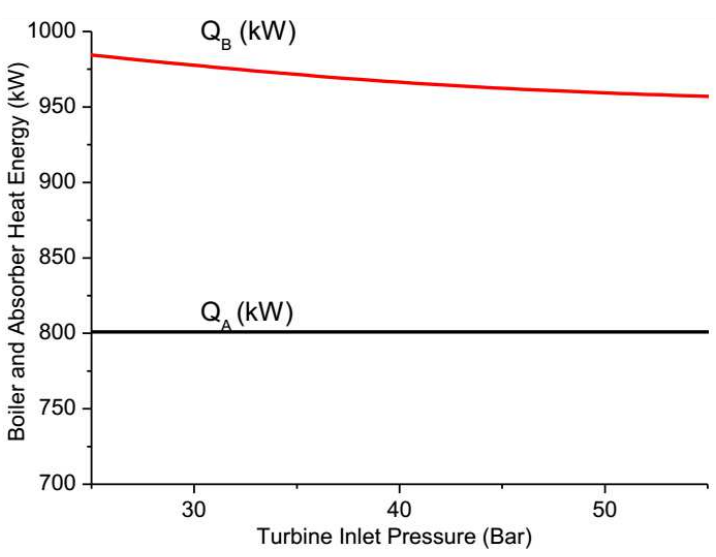

Fig. 4. Variations of the absorber and the boiler heat energies with turbine inlet pressure of the ammoniawater cycle. 
Variations of the absorber and the boiler heat energies with turbine inlet pressure (between 25-55 Bar) of the ammonia-water cycle are given in Fig. 4 . The turbine inlet pressure has no effect on the absorber heat energy, so that increasing the turbine inlet pressure does not make any effect on it. As can be seen in Table II, the reason for that is that the outlet turbine pressure is taken constant, so that the properties of the inlet streams of the absorber are the same for each pressure.

TABLE II

Thermodynamic properties of the streams of the ammonia-water cycle for pump outlet pressure of 40 bar.

\begin{tabular}{|c|c|c|c|c|c|c|c|c|c|c|c|}
\hline $\begin{array}{c}\text { Stream } \\
\text { no. }\end{array}$ & Fluid & Description & Phase & $\begin{array}{c}\text { Pressure } \\
{[\mathrm{kPa}]}\end{array}$ & $\begin{array}{l}\text { Temp. } \\
{\left[{ }^{\circ} \mathrm{C}\right]}\end{array}$ & $\begin{array}{c}\text { Concen. } \\
{\left[\mathrm{kg} \mathrm{NH}_{3} /\right.} \\
\mathrm{kg} \operatorname{mix}]\end{array}$ & \begin{tabular}{|c|} 
Flow \\
rate \\
{$[\mathrm{kg} / \mathrm{s}]$}
\end{tabular} & $\begin{array}{c}\text { Enthalpy } \\
{[\mathrm{kJ} / \mathrm{kg}]}\end{array}$ & $\begin{array}{c}\text { Energy } \\
{[\mathrm{kW}]}\end{array}$ & $\begin{array}{c}\text { Entropy } \\
{[\mathrm{kJ} / \mathrm{kg} \mathrm{K}]}\end{array}$ & $\begin{array}{c}\text { Exergy } \\
{[\mathrm{kW}]}\end{array}$ \\
\hline 0 & Ammonia & - & - & 100 & -50 & - & - & 118.47 & - & 0.5659 & - \\
\hline 1 & $\begin{array}{c}\text { Weak } \\
\text { aqua-am. }\end{array}$ & HE inlet & $\begin{array}{l}\text { Saturated } \\
\text { liquid }\end{array}$ & 4000 & 200 & 0.126 & 0.53 & 829.1 & 376.6 & 2.7 & 124.4 \\
\hline 2 & $\begin{array}{c}\text { Weak } \\
\text { aqua-am. }\end{array}$ & PRV inlet & $\begin{array}{l}\text { Cooled } \\
\text { liquid }\end{array}$ & 4000 & 15 & 0.126 & 0.53 & -14.1 & -70.3 & 0.41 & -51.9 \\
\hline 3 & $\begin{array}{c}\text { Weak } \\
\text { aqua-am. }\end{array}$ & Absor. inlet & $\begin{array}{l}\text { Cooled } \\
\text { liquid }\end{array}$ & 200 & 15 & 0.126 & 0.53 & -14.1 & -70.3 & 0.42 & -53 \\
\hline 4 & $\begin{array}{c}\text { Strong } \\
\text { aqua-am. }\end{array}$ & Pump inlet & $\begin{array}{l}\text { Saturated } \\
\text { liquid }\end{array}$ & 200 & 7 & 0.54 & 1 & -31.5 & -150 & 0.666 & -172.3 \\
\hline 5 & $\begin{array}{c}\text { Strong } \\
\text { aqua-am. }\end{array}$ & HE inlet & Liquid & 4000 & 7 & 0.54 & 1 & -20.5 & -139 & 0.665 & -161 \\
\hline 6 & $\begin{array}{c}\text { Strong } \\
\text { aqua-am. }\end{array}$ & Boiler inlet & $\begin{array}{c}\text { Saturated } \\
\text { liquid }\end{array}$ & 4000 & 100 & 0.54 & 1 & 423.1 & 304.6 & 2.04 & -24.1 \\
\hline 7 & Ammonia & Turbine inlet & S.heated vapor & 4000 & 200 & 1.00 & 0.47 & 2004.8 & 886.6 & 6.1 & 306.5 \\
\hline 8 & Ammonia & Cooler inlet & S.heated vapor & 200 & -15 & 1.00 & 0.47 & 1587.4 & 690.4 & 6.3 & 89.4 \\
\hline 9 & Ammonia & Absorb inlet & S.heated vapor & 200 & 7 & 1.00 & 0.47 & 1642.9 & 716.5 & 6.6 & 84.1 \\
\hline Overall & $\begin{array}{r}\text { Cooler } \\
\text { H } \\
\text { cycle exerg }\end{array}$ & $\begin{array}{r}\text { Pump } \\
\text { heat energy-e } \\
\text { Boiler heat } \\
\text { Teat exchanger } \\
\text { gy destruction } \\
\text { Energy } \\
\text { Exergy }\end{array}$ & $\begin{array}{l}\text { Nork energy } \\
\text { xergy-exergy des } \\
\text { energy-exergy } \\
\text {-exergy destruct } \\
\left(E_{\mathrm{D}, \mathrm{OC}}=E_{\mathrm{Q}, \mathrm{B}}\right. \\
\text { efficiency } \\
\text { efficiency }\end{array}$ & $\begin{array}{l}\text { struction } \\
\text { ion } \\
+W_{\mathrm{P}}-1\end{array}$ & $\left.\Gamma-E_{\mathrm{QC}}\right)$ & $Q_{\mathrm{C}}=$ & $\begin{array}{r}26 \mathrm{~kW}, \\
Q_{\mathrm{B}}=\end{array}$ & $\begin{array}{r}795 \mathrm{~kW}, E \\
W_{\mathrm{T}}= \\
W_{\mathrm{P}}= \\
E_{\mathrm{QC}}=5 . \\
=958 \mathrm{~kW}, \\
E_{\mathrm{D}, \mathrm{HE}}= \\
E_{\mathrm{D}, \mathrm{OC}}= \\
0 . \\
0 .\end{array}$ & $\begin{array}{l}\mathrm{D}_{\mathrm{D}, \mathrm{A}}=20 \\
197 \mathrm{~kW} \\
11 \mathrm{~kW} \\
6 \mathrm{~kW}, E \\
E_{\mathrm{Q}, \mathrm{B}}= \\
39.4 \mathrm{~kW} \\
107.4 \mathrm{~kW} \\
23 \\
68\end{array}$ & $\begin{array}{l}{ }_{\mathrm{D}, \mathrm{C}}=10.9 \\
299 \mathrm{~kW} \\
\mathrm{~V}\end{array}$ & $\mathrm{~kW}$ \\
\hline
\end{tabular}

\section{Conclusions}

For some special conditions ammonia water power cycle is an important and economical option. By adding new components into the ammonia-water cycle, different kind of cycles can be obtained such as Goswami cycle, Kalina cycle, and other proposed cycles. This cycle has no effects on the destruction of environment and global warming, because it uses natural working fluid. For most of applications the ammonia water cycle produces more power than the Rankine cycle, it can be used as a bottoming cycle for gas turbines, gas engines, diesel engines, geothermal power cycles and other industrial power cycles. Using low temperature waste heat sources is a real need for the industry. For that reason improving the efficiency of the ammonia water cycle is important.

There is no mass inlet or outlet of the cycle so that the chemical exergy of the streams are not taken into calculations. The physical exergy of the streams are calculated as the total exergy. There is boiling process and heat transfer at low temperature which both destruct the energy given into the boiler, so that the energy efficiency is low, however the exergy efficiency is higher than the energy efficiency. Increasing the turbine inlet pressure of the ammonia-water cycle decreases the energy and exergy efficiencies, which is in agreement with literature. The turbine inlet pressure cannot make any effect on the absorber heat energy, since the outlet turbine pressure is 
taken constant, so that the properties of the inlet streams of the absorber for each pressure are the same. The optimum turbine inlet pressure can be obtained with an optimization study of the ammonia-water cycle for each working condition.

\section{References}

[1] D.S. Ayou, J.C. Bruno, R. Saravanan, A. Coronas, Renew. Sust. Energ. Rev. 21, 728 (2013).

[2] H. Cho, A.D. Smith, P. Mago, Appl. Energ. 136, 168 (2014).

[3] A.I. Kalina, J. Eng. Gas Turb. Power 106, 732 (1984).

[4] V. Zare, S.M.S. Mahmoudi, M. Yari, Energy 61, 397 (2013).

[5] V. Zare, S.M.S. Mahmoudi, M. Yari, Appl. Therm. Eng. 48, 176 (2012)

[6] C. Dejfors, E. Thorin, G. Svedberg, Energ. Convers. Manage. 39, 1675 (1998).

[7] J. Wang, Z. Yan, M. Wang, Y. Dai, Energy 50, 513 (2013).
[8] J. Wang, J. Wang, P. Zhao, Y. Dai, Energy 117, 335 (2016).

[9] M. Jonsson, J. Yan, Energy 26, 31 (2001).

[10] F. Xu, D.Y. Goswami, S.S. Bhagwat, Energy 25, 233 (2000).

[11] R.V. Padilla, G. Demirkaya, D.Y. Goswami, E. Stefanakos, M.M. Rahman, Energy 35, 4649 (2010).

[12] F. Xu, Ph.D. Thesis, University of Florida, 1997.

[13] R. Tillner-Roth, D.G. Friend, J. Phys. Chem. Ref. Data 27, 63 (1998).

[14] G.S. Alamdari, IJE Trans. B: Applications 20, 97 (2007).

[15] G.S. Alamdari, IJE Trans. A: Basics 20, 95 (2007).

[16] D. Sun, Appl. Therm. Eng. 17, 211 (1997).

[17] K. Annamalai, I.K. Puri, Advanced thermodynamics engineering, CRC Press LLC, 2002.

[18] I. Dincer, M.A. Rosen, Exergy, energy, environment and sustainable development, 1st ed., Elsevier Ltd., 2007. 